\title{
Health Promotion Programs for the Elderly in Greece, the "Health Pro Elderly" Project
}

\author{
Panayota Sourtzi, Vasiliki Roka, \\ Venetia Velonaki and Athena Kalokerinou
}

\section{Introduction}

The ageing of the population and the increase in the incidence of chronic diseases, combined with limited resources for health care, led researchers and policy makers to search for health promotion alternatives. Defining Health Promotion as the process of enabling people to increase control over their health in order to improve it ${ }^{1}$ and considering Healthy Ageing as an approach which recognizes that growing older is a part of living fostering a positive attitude through life to growing older ${ }^{2}$, "Health pro Elderly" project was designed and realised in order to develop evidence-based guidelines and recommendations about action in European, National and Local level.

European reality reveals an unprecedented demographic change characterised by a remarkable ageing of the population, as a result of the general increase in the standard of living as well as of the whole progress of health sciences and medical technology. Proportionally, in Greece, the expectancy of life rose from 74, 6 years for males and 79, 4 for females in 1990 to 75, 42 and 80, 54 respectively in 2000. Besides, in 2000, the population aged over 65 was $16.6 \%$, while in 2005 was $18 \%^{3}$ and in 2050 it is expected to reach the percentage of $31,5 \%$ of the general population $^{4}$. The increase of life expectancy, combined with the increase in the ageing index has important social and political implications, as fewer people of productive

1 WHO, Health Promotion Glossary WHO/HPR/HEP/98.1 (Geneva, 1998), pp. 1-2.

2 WHO, A Glossary of Terms for Community Health Care and Services for OlderPersons. WHO/WKC/Tech.Ser./04.2. (Geneva, 2004), p. 31.

3 National Statistical Service of Greece, Statistical Yearbook of Greece and Monthly Statistical Bulletin (NSSG Census, 2001).

4 Eurostat, EU25 population aged 65 and over expected to double between 1995 and 2050 (Eurostat Press Office, 129/2006). 
age will support the increasing demands on the health care system. Substantial adjustments and provisions in health care systems are required. Health promotion and prevention need to be developed in order to reduce the necessity for cure and care with respect to Health as a basic human value and an important resource for every day life.

In this context Health Promotion Programs for the Elderly become very important. In most EU countries, many health promotion activities for seniors take place, but they are not always properly evaluated or sustainable. The "Health Pro Elderly" project aims to identify criteria that make health promotion programs successful and provide evidence for sustainability.

\section{Health Promotion for the Elderly}

It is possible to improve the quality of life of older people by empowerment, physical and mental activity. Older people can - with successful health promotion interventions - be empowered to lead a healthy life, increase their social contacts, stay physically active and live independently.

Different types of health promotion activities for older people, including environmental adaptation, which make active ageing possible represent a new and innovative field that is vital for the future. There are various individual projects and programmes in EU-member states that offer health promotion activities on a local or regional level. However, they are frequently not known on a national or international level. Besides, limited funding, lack of mainstream provision and no coherent policies in this field undermine the continuity and sustainability of the programs despite the expertise and the Know-how of the involved stuff.

The evaluation of existing health promotion programs, projects and initiatives is essential as it can contribute a lot to the determination of the elements that make a current health promotion practice successful and will serve as models of good-practice in the field of health promotion for older people.

An essential point of the evaluation of health promotion interventions for the elderly is that they involve a great number of stakeholders with different interests, priorities and understandings of what can be characterised as important and what not. For instance, users, carers, professionals, funding institutions and researchers have differences in their point of view about relevant health promotion initiatives.

Regarding existing health promotion programs and projects in European level it is obvious that in their majority they have a target group between 55 and 65 years of age and many of them define their target group with certain group characteristics. Many of them include invisible older people, considering as invisible a group basically economically dependent and passive, neglected by politicians and the official state that generally focuses on younger groups of population. Besides, the majority 
of existing health promotion initiatives focuses on one aspect of health, the physical, mental, or social one and less on an holistic approach. Additionally, some of them consider healthy environments and structures as an important aspect of health promotion for the Elderly. Seldom initiatives include both, individuality and macro-society in their initial concept $t^{5}$. Besides, the majority of existing programs and projects are realised into community settings, particularly in urban areas and their stakeholders belong as a rule more to public sector, for instance ministries, municipalities, city councils, universities and educational institutions, health care infrastructures and less to non-profit and to private/profit sector. Regarding their goals, it is obvious that the majority of the projects aim at the development of personal skills and very few refer to a systemic approach focusing on individual's environments and supportive structures ${ }^{6}$.

All the stakeholders broadly support the involvement of the target group in all phases of health promotion initiatives. It is very important to involve the elderly as they can specify their own needs and determine the ways of approach within health promotion practice.

It is obvious that successful health promotion for older people is a complex issue and needs massive planning. During the phase of planning specific characteristics of the target group have to be considered as well as the documentation and the theoretical background which suits to the interventions, taking into consideration the goals and aims. Besides this, the determination of the proper setting for the intervention and the management and the financial structures is essential too. Proportionally, during the phase of implementation, the activation of older people is essential, combined with the stimulation of social and political networks. Finally, during the phase of evaluation, both qualitative and quantitative evaluation designs have to be used so as to assess both process and outcomes ${ }^{7}$.

\section{The "Health Pro Elderly" Project}

"Health Pro Elderly" is a Project realised within the Public Health Program of the European Commission, financed by European and National resources, from April 2006 until December of 2008. The project's partners come from eleven countries, including Austria, Czech Republic, Germany, Greece, Italy, Netherlands, Poland,

5 Gert Lang, Katharina Resch. 33 European Best-Practice Projects: A Case-Study Evaluation of Health Promotion for Older People, (Research Institute of the Red Cross, July 2008).

6 URL Health pro elderly, Health pro elderly, Evidence-based Guidelines on Health Promotion for Older People: Social determinants, Inequality and Sustainability.

7 Lang\& Resch, (2008). 
Slovenia, Slovakia, Spain, and United Kingdom. Red Cross of Austria was the overall co-coordinator and the independent Institute "Emmeerre "(Italy) has been put in charge of the Evaluation of the project. The project's partners represented an interdisciplinary team involving professionals from university institutions (7), Red Cross Associations (4), non-university research institutions (2), nurses' organizations (2) and Public Health organisations (2).

The overall aim of the project was to support Health promotion for older people via developing evidence-based guidelines and recommendations for action in European, National and Local level. While, General Objectives of the project included:

- a literature overview and the writing of relevant National reports, forming an Excel database;

- the collection of all relative terms in a glossary;

- the selection of a set of inclusion and exclusion criteria to choose and assess national health promotion programs for the elderly that serve as examples of good practice;

- the recognition of criteria that contribute to the success of health promotion programs;

- the composition of evidence based guidelines and recommendations for Health promotion for the Elderly and

- the dissemination of the knowledge produced of the project in National and European level.

The project was realized within five phases.

During the first phase (July 2006- January 2007), a literature review was compiled and the terminology used was gathered in a glossary, in order to create a common base of communication, in English, given the different languages of the partners. Besides, a set of inclusion and exclusion criteria for the selection of national health promotion models of good practice was composed.

During the second phase (January 2007- May 2007), the collection and compilation of several national health promotion models took place, according to eligibility criteria agreed on the first phase. These models formed a database of more than 160 items.

During the third phase (May 2007- January 2008), each partner selected three models of good practice and evaluated them in detail, according criteria focusing on vulnerability, sustainability and inequality. Relevant national reports were formed and then a European report was formed as well.

During the fourth phase (January 2008- May 2008), an international congress, in Warsaw, Poland was organized by Polish National Nurses Association. In that conference the results of the three previous stages were presented and the first draft of the recommendations and guidelines was formed. 
During the last phase (May 2008- December 2008), the development of evidence- based guidelines and recommendations took place ${ }^{8}$.

All the material produced during the project have been located to the project's website, available at www.healthproelderly.com.

\section{The Greek case}

Greek project partners, throughout the literature search ascertained that the majority of the collected data reflected the situation in a local, of regional level and less in the national level. The overwhelming majority of studies and projects concerned KAPIs, open health care centers for the elderly and fewer community and residential homes for older people. Furthermore, there was a significant interrelatedness of different themes and issues in many sources of the literature. The whole number of the literature findings referred to the quality of life and health determinants in broad terms.

So, many of the sources emphasized on the quality of life of old people who suffer from mental disorders, especially people with Alzheimer's disease. Issues concerning lifestyle were proportionally common themes in literature. Nutrition, safety, and disease prevention were addressed in a considerable number of sources ${ }^{9}$.

All literature findings have been compiled in an excel-database available in the website of the project.

Among all the programs, projects and studies from Greece, three projects were selected according to the criteria of "Health Pro Elderly" project. These projects were all effectively developed and implemented. "Action programme for older people", "The involvement and the role of older volunteers in promoting healthy diet for the prevention of cardiovascular diseases" and "The role of Health Education in Improving Compliance with treatment for the Prevention of Cardiovascular Diseases" are the three case studies; each one was a Health Promotion intervention which took place in different urban municipalities in the greater Athens area and constituted an innovative and crucial initiative which dealed with older people and undertook health promotion action. These last two programmes were selected from the other programmes in the database because of their well-grounded theoretical approach and strategy. Additionally, these programmes were selected as they included empowerment, voice of older people and evaluation. On the other hand, the "Action programme for older people" was mainly selected because it has been running for more than 10 years (sustainability), it was accessible for all older people

8 URL Health pro elderly, (2009).

9 Athena Kalokerinou, Theodoula Adamakidou, Maria Damianidi, Vasiliki Roka, Venetia Velonaki, Panayota Sourtzi, National Evaluation Report- Greece. (Health Pro Elderly URL, 2008). 
of the municipality where it took place and because of its transferability. All presented health promotion programmes have been properly evaluated and widely disseminated and took place within Open Care Centres for Older People (KAPI).

According Greek reality, KAPIs are centres that accept as members any older person over 60 years old. In KAPIs a small number of health and social care professionals, such as nurses/health visitors, social workers, physiotherapists, occupational therapists, home care assistants. Their role is to promote the health of older people in any available way. KAPIs are widespread throughout the country and are very popular with older people of both sexes. There are over 450 KAPIs today in Greece run by the local authorities; while in the everyday running of the centre older people are seriously involved as some of them are elected to participate in the administrative body of each centre ${ }^{10}$.

The first project, "Action Programme for older people" focused on maintenance and improvement of mobility, autonomy and self-care, via an exercise program. It has been implemented since 1997, in the municipality of Agios Dimitrios (greater Athens area). Mr Babanas A. and Ms Koureta K. have been the major contributors. The project has been based on previous related projects co-ordinated by the General Secretariat for Sports. These projects have been implemented in different KAPIs in different municipalities. The project is run and staffed by the local Primary Health Care Services. The target group of the project has been people older than 60 years old. The action programme for older people has been implemented in two phases. In the first phase, the elderly are informed through lectures and discussions about health related problems and the role of exercise in the improvement of their health. The second phase included the action programme, which takes place in a special room (gym) and in outdoor athletic areas, using appropriate exercise aids. The duration of the programme is 45 minutes each time and it has taken place twice a week. Each year the participants' physical state and mobility is evaluated. The entire project is evaluated every 5 years. The results of the project are the improvement of participants' joint functional ability and mobility; the improvement of neuromuscular control on the movements and of body balance; the adoption of healthier habits and less frequent use of physiotherapy ${ }^{11,12}$.

The second project, "The involvement, and the role of older volunteers in promoting healthy diet for the prevention of cardiovascular diseases", has promoted the Senior Health Mentoring concept as a model for spreading out health promotion issues through Day Care Centres. Dr Velonakis E. and Dr Sourtzi P. were the

10 Kalokerinou et al., (2008).

11 Emanuel Papadakakis, Athanasios Babanas, Katerina Koureta, Action Programme in older people, in Proceedings: "Subjects of Gerontology and Geriatrics/ The current greek experience at the begging of third millennium" (Publishers: "Synedron: Dimiourgikes ekdosis", 2000), pp 43-48.

12 Anonymous, Happy years, full of action and energy (Energos Dimotis Notion Proastion, 2007), p12. 
co-ordinators of the project, which took place in Open Care Centres for Elderly (KAPI) in two Municipalities in greater Athens area and was co-financed by the European Commission and by National funds. This project was designed as a pilot study, in order to examine the feasibility of developing the Senior Health Mentoring concept, which is referring to the involvement of older people themselves in health promotion activities, by reinforcing their existing experience with appropriate knowledge, as a model for spreading out health promotion issues. During the first phase of the project, a number of older volunteers were trained in teaching and communication principles, as well as contemporary nutritional information based on the Mediterranean diet. In the second phase of the project, the trained volunteers started spreading out their new knowledge in their respective KAPIs as well as in KAPIs of other municipalities in the greater Athens area. Following the successful evaluation of the project an information package was produced; this was sent out to all KAPIs in the country and has been used by health professionals in other KAPIs, until nowadays. The results of this project include high Senior Mentors satisfaction; changes in their own lives; useful published educational material and sharing of the knowledge with others as friends and relatives ${ }^{13,14}$.

The third project, "The Role of Health Education in Improving Compliance for the Prevention of Cardiovascular Diseases", focused on access to preventive activities and healthier lifestyles. Dr Varsamis E., Dr Velonakis E. and Dr Sourtzi P. were the co-ordinators of the project, which took place in two Open Care Centres for Elderly (KAPI), in the municipality of Nea Ionia (greater Athens area) and was co-financed by the European Commission and by National funds. This project was a health education programme with main objectives the access and adoption of healthier lifestyles towards cardiovascular risks in older people. The results of this intervention were compared with those in a control group of the other two KAPIs in the same city, where no health intervention was implemented. The results of the project included the reduction of body weight of the participants; a healthier lifestyle; more regular measurement of blood pressure and glucose and more regular visits to the physician ${ }^{15,16}$.

13 Panayota Sourtzi, Anastasia Amanatidou, Emanuel Velonakis, Evaluation of a training programme for Volunteer Senior Health Mentors in Healthy Nutrition, Primary Health Care (Greek), (2003), volume 15, pp 108-115.

14 Emanuel Velonakis, Panayota Sourtzi, Anastasia Amanatidou, Panayota Kaligeri Vithoulka, Fred Hunt, Final report of the project: "The involvement and the role of older volunteers in promoting healthy diet for the prevention of cardiovascular diseases" (Publisher: Hellenic Association of Gerontology and Geriatrics, 1999), pp 1-83.

15 Emanuel Velonakis, Panayota Sourtzi, Nikolaos Komitopoulos, Dimitrios Ioannidis, Eystratios Varsamis, 1999, A health promotion programme for the prevention of cardiovascular diseases in the elderly. Health Prom. \& Educ., (1999), 37(1): 26-29. 


\section{Conclusions}

The lack of resources and personnel could be balanced by promoting policies that will advance Healthy Ageing. "Health Pro Elderly" as part of a EU-wide health promotion policy contributes to that direction. In this context Greek reality reveals that organized health promotion endeavors take place in Greece but in their majority they are implemented in the KAPIs, mainly in urban areas. This fact indicates inequalities in health. Besides, the selected three models of best-practice in health promotion for the elderly, as incorporated in "Health Pro Elderly" project, aim to promote health and prevent certain diseases and disability via interventions focusing on individuals' behavior and attitude without dealing with macro-society's relevant factors.

On the other hand, the material developed during these projects, such as valuable handbooks and leaflets, can be used for wide dissemination of the experience obtained within these projects and help out any one interested in implementing such programmes or in developing them further.

In broad terms, with "Health Pro Elderly" project a variety of health promotion activities all over Europe have shown their effect on improving the quality of life of older people, indicating the importance of such initiatives and the necessity for the sustainability and transferability of them despite the limited resources and the lack of mainstream provision. These projects have built up Know-how and expertise and have stressed some key- points in order to provide the basis for the development of successful health promotion activities for the elderly. Among these key-points belong:

- the information campaigns focusing on the positive effects of the initiatives presented;

- the development of national health promotion programmes for the elderly respecting their heterogeneity;

- the maintenance of successful programmes in order to meet the needs of older groups of the population;

- the creation of networks in national and local level, supporting the exchanges of information between the stakeholders;

- the enhancing of the importance of continuing training for the involved professionals in order to have the knowledge, skills and tools demanded for effective and productive health promotion interventions;

- the supporting of relevant research activities and

16 Eystratios Varsamis \& Emmanuel Velonakis, Final report of the project The role of Health Education in Improving Compliance for the Prevention of Cardiovascular Diseases, (1999), pp $1-94$. 
- the promotion of the dissemination of models of good practice in health promotion for the elderly ${ }^{17}$.

In conclusion, "Health Pro Elderly" project constitutes an essential health promotion initiative for the elderly, which contributes decisively to the whole effort of health promotion, so as to relieve the Health Care systems of the Members States of the European Union. The lack of sources and personnel could be balanced with potential action in this field through a common policy, strategies, guidelines and recommendations for priority actions for Healthy Ageing.

Panayota Sourtzi is RN, Ph.D., Associate Professor in Nursing Department, National and Kapodistrian University of Athens, Greece.

Vasiliki Roka is RN, MSc, Ph.D. National and Kapodistrian University of Athens, Naval Officer, Military Nursing Academy, Greece.

Venetia-Sofia Velonaki is RN, MSc, Ph.D.(c) National and Kapodistrian University of Athens, Greece.

Athena Kalokerinou is RN, Ph.D., Associate Professor in Nursing Department, National and Kapodistrian University of Athens, Greece.

17 Lang\& Resch, (2008). 


\section{References}

Anonymous, Happy years, full of action and energy, Energos Dimotis Notion Proastion (2007), 12.

Eurostat, EU25 population aged 65 and over expected to double between 1995 and 2050, Eurostat Press Office, 129/2006, available at http://epp.eurostat.ec.europa.eu, accessed 13 June 09.

Kalokerinou, Athena, Theodoula Adamakidou, Maria Damianidi, Vasiliki Roka, Venetia Velonaki, Panayota Sourtzi, National Evaluation Report- Greece. Health Pro Elderly URL ,2008. Available at

http://www.healthproelderly.com/pdf/National_Evaluation_Report_Greece fi nal.pdf, accessed 13 June 09.

Lang, Gert, Katharina Resch. 33 European Best-Practice Projects: A Case-Study Evaluation of Health Promotion for Older People. Research Institute of the Red Cross, July 2008. Available at http://www.healthproelderly.com/pdf/hPe European Evaluation Report 200 80728 (final).pdf, accessed 13 June 09.

National Statistical Service of Greece, Statistical Yearbook of Greece and Monthly Statistical Bulletin, NSSG Census, 2001. Available at

http://www.statistics.gr/Main eng.asp, accessed 13 June 09.

Papadakakis, Emanuel, Athanasios Babanas, Katerina Koureta, Action Programme in older people, in Proceedings: "Subjects of Gerontology and Geriatrics/ The current greek experience at the begging of third millennium" ,Publishers: "Synedron: Dimiourgikes ekdosis" (Athens, 2000), pp 43-48.

Sourtzi, Panayota, Anastasia Amanatidou, Emanuel Velonakis, Evaluation of a training programme for Volunteer Senior Health Mentors in Healthy Nutrition, Primary Health Care (Greek), volume 15(2003), 108-115.

URL Health pro elderly, Health pro elderly, Evidence-based Guidelines on Health Promotion for Older People: Social determinants, Inequality and Sustainability. Available at http://www.healthproelderly.com/pdf/Glossary hpe.pdf, accessed 13 June 09.

Varsamis, Eystratios, Emmanuel Velonakis, Final report of the project The role of Health Education in Improving Compliance for the Prevention of Cardiovascular Diseases (Athens. 1999), 1-94.

Velonakis, Emanuel, Panayota Sourtzi, Anastasia Amanatidou, Panayota Kaligeri Vithoulka, Fred Hunt, Final report of the project: "The involvement and the role of older volunteers in promoting healthy diet for the prevention of cardiovascular diseases" , Publisher: Hellenic Association of Gerontology and Geriatrics (Athens, 1999). pp 1-83. 
Velonakis, Emanuel, Panayota Sourtzi, Nikolaos Komitopoulos, Dimitrios Ioannidis, Eystratios Varsamis, A health promotion programme for the prevention of cardiovascular diseases in the elderly. Health Prom.\&Educ., 37(1) (1999), 2629.

WHO, Health Promotion Glossary, WHO/HPR/HEP/98.1, pp. 1-2. Geneva, 1998. Available at http://www.who.int/hpr/NPH/docs/hp glossary en.pdf , accessed 13 June 09.

WHO, A Glossary of Terms for Community Health Care and Services for Older Persons, WHO/C/Tech.Ser./04.2,p.31.Geneva,2004. Available at http://whqlibdoc.who.int/wkc/2004/WHO WKC Tech.Ser. 04.2.pdf, accessed 13 June 09. 